\title{
Advanced roles for nurses working in general practice: A study of barriers and enablers for nurses in rural Australia
}

\author{
Karen Francis ${ }^{1}$, J udith Anderson ${ }^{2}$, Narelle Mills ${ }^{3}$, Tony Hobbs ${ }^{4}$, Mary Fitzgerald ${ }^{5}$ \\ 1. School of Nursing, Midwifery and Indigenous Health, Charles Sturt University, Wagga Wagga, Australia. 2. School of \\ Nursing, Midwifery and Indigenous Health, Charles Sturt University, Bathurst, Australia. 3. Murrumbidgee Medicare Local, \\ Wagga Wagga, Australia. 4. Cootamundra Primary Health Centre, Cootamundra, Australia. 5. School of Nursing, Midwifery \\ and Indigenous Health, Charles Sturt University, Wagga Wagga, Australia.
}

Correspondence: Karen Francis. Address: School of Nursing, Midwifery and Indigenous Health, Bldg 2/314 - Locked Bag 588, Charles Sturt University, Wagga Wagga, NSW 2678, Australia. Email: kfrancis@csu.edu.au

Received: May 12, 2013

DOI : $10.5430 /$ cns.v1n4p45
Accepted: August 27, 2013

URL: http://dx.doi.org/10.5430/cns.v1n4p45

\section{Abstract}

Rural Australians have poorer access to health services than Australians living in metropolitan areas primarily because of shortages in the health professional workforce. Nurses taking on advanced skills could help this situation by relieving doctors but our understanding of the factors that enhance or inhibit uptake is poorly understood in rural areas of Australia.

The aim of this study is to identify the barriers and enablers associated with the implementation of advanced nursing roles in rural general practice specifically although an urban general practice was included to ensure that the diversity of practices were represented. The selection of general practices was based on (1). a standardised classification system that uses geographic location and population base as the key criterion and (2). ease of access for the research team. The general practices were all located within 3 hours drive of the researchers' home base. Using case study design four rural and one metropolitan located general practices were included. The researchers compared recorded nursing activities with job descriptions, educational opportunities and advanced competency standards. Interviews with practice principals, practice managers and nurses were undertaken. Findings are categorised as: personal which includes motivation, knowledge and time; workplace which includes status, guidelines and practice conventions and routines; and policy which includes national payment systems, and scope of practice. The potential for nurses to advance their practice and meet the needs of patients, particularly in the specialist areas of chronic care and health promotion, is still under developed in the rural practices. The findings have led to the development of a framework for the introduction of advancing practice roles for nurses that will meet the needs of a currently, under-served community.

\section{Key words}

Practice nursing, Advanced practice, Rural Australia, Primary health care, Case study

\section{Introduction}

Well over ten years ago the shortage of doctors in rural Australia resulted in new funding from the Australian Government to support the employment of nurses in general practice to augment service providers in this context and thus support the 
adoption of new models of care ${ }^{[1]}$ that would improve patient access to health services in rural Australia. Despite the investment, the extent to which general practice nurses are advancing their practice and meeting the needs of rural communities by working to the full extent of their scope of practice is debatable. This study was set up to investigate the degree to which nurses in general practice are enabled or inhibited from working to the full extent of their knowledge and skills and thereby helping significantly to sustain high quality primary health care services in rural Australia.

\section{Literature review}

In 2006 a general practice nurse was defined as “ ...a qualified nurse who provides nursing management in the general practice setting under some degree of supervision from the employing general practitioner” ${ }^{[2]}$. The Australian General Practice Network ${ }^{[3]}$ offers the following definition:

A practice nurse is a registered nurse or an enrolled nurse (Division 1 and 2 in Victoria) who is employed by, or whose services are otherwise retained by, a general practice ${ }^{[3]}$.

Halcomb et al., ${ }^{[2]}$ commented that in 2006 the role of nurses in general practice was limited, with nurses undertaking tasks to assist doctors manage and treat illness and injury. However, Keleher et al., ${ }^{[4]}$ reported that nurses in primary care settings, inclusive of general practices, can provide effective care and achieve positive health outcomes for patients similar to that provided by doctors.

Working in collaboration within scope of practice is touted as the appropriate model for nursing in this context of practice ${ }^{[3]}$. The Royal College of Nursing Australia (RCNA) developed a kit to provide general practice teams with direction on the roles, responsibilities, legal requirements underpinning nurse's practice and human resource issues ${ }^{[5]}$. The guidelines assert that the role of the general practice nurse is unique and complimentary to that of other health professionals including medical doctors. The work of nurses in general practice involves: the provision of clinical care such as triaging patients, health assessment, first aid, medication administration, health promotion and diagnostic testing; management of clinical care systems such as maintaining best practice procedures through current research, use of recall registers and other workplace systems, maintaining clinical records and reports; collaborative practice; and engaging in collaborative practice through communicating with team members, participating in decision making and keeping up to date with local, national and international trends, practices and events ${ }^{[5]}$. Phillips et al ${ }^{[6]}$, grouped these into six broad operating roles: patient care; quality controller; organiser; problem solver; educator; and agent of connectivity.

Negotiating scope of practice is a complex evolving process. Initial employment as a general practice nurse is often against an existing job description. This job description may have been developed by the practice to meet their needs with little understanding of the role of the nurse or how this could be developed. For the role of the general practice nurse to mature and advance, negotiation with the general practice team must occur together with modification to the nurse's job description reflecting the changes agreed to ${ }^{[7]}$. Changes to the role of the nurse may be instigated by the practice as an outcome of accessing new funding streams, rethinking the operations of the practice, and/or the nurse identifying options for new work practices ${ }^{[6]}$ that align with the strategic vision of the workplace.

Phillips et al., ${ }^{[6]}$ indicate that the roles of nurses in general practice are influenced by three levels: structural determinants; practice level determinants and individual determinants. This acknowledges the environment and culture of each individual practice in its influence on advanced and extended practice. Structural determinants such as legal implications are also supported by other literature ${ }^{[8,9]}$. In particular Phillips et al., ${ }^{[6]}$ point out that the balance of power and notions of 'proper' hierarchical relationships between the nurses and doctors affects the ability of nurses to extend their practice in relation to decision making in patient care, task or responsibility delegation and overall autonomy. Caldow et al., ${ }^{[10]}$ discuss another aspect of "individual determinants", that of patient acceptance. Their questionnaire, completed by 1343 general practice patients in Scotland, revealed that if patients were informed of nurses' capabilities they would be 
accepting of nurses taking on roles previously undertaken by general practitioners. A similar study ${ }^{[11]}$ in Australia also found that patients $(n=106)$ were comfortable with nurses in general practice expanding their roles. However in a qualitative study that interviewed 28 patients in the United Kingdom, Redsell et al., ${ }^{[12]}$ found that patients continued to prefer general practitioners to nurses due to their perceived greater skills, knowledge and authority.

As nurses in general practice gain skills and competence, negotiation with General Practitioners to expand their practice occurs. For example Mills and Fitzgerald ${ }^{[13]}$ reported that nurses in general practice were supported by their employing General Practices to undertake professional development relevant to the workplace, such as credentialing for cervical screening of women. They further commented that even after completing a credentialing program they were not always permitted to provide the service item as part of their role without negotiating with the general practice to add this activity to their scope of practice ${ }^{[13]}$. In their action research study of a general practice in England, Galvin et al. ${ }^{[14]}$ described difficulties in advancing practice which were partially due to a lack of leadership within the nursing team.

It appears from the evidence to date that nurses are more than capable of taking on advanced practice roles in general practice. However, what is missing in the literature is why uptake has been so slow in rural Australia or what could be done to encourage advanced roles.

\section{Methodology}

A multiple case study design was used to identify the current role/s, scope of practice of nurses in one region of Australia that is primarily rural and the barriers and enablers to extending their practice ${ }^{[15]}$ in that specific context. Case study was chosen because general practices in Australia are not homogenous and attention to context is important when encouraging change. Purposive sampling was chosen to ensure that rurality featured in the case selection as little is known about practice nursing in rural contexts. Each case study was reported separately for local use - the accumulated results are reported in this paper.

\subsection{Definition}

There is no agreed definition on advanced general practice nursing. Advanced roles were specifically mentioned in the commissioning brief and our verified understanding of this was the following:

Advanced practice in general practice nursing is expanded or extended roles that are within the scope of practice of registered nurses but not previously undertaken in the general practice and that require specialist knowledge and experience.

\subsection{Data collection methods}

Diaries: A diary template was developed to collect frequency data on the various activities undertaken by the nurses from each of the five general practices. The diary template was tested (by three practice nurses not participating in the main study) for ease of use and was revised accordingly. All nurses who agreed to participate in the study were given a booklet containing the diary template and instructions on how to complete the diary over a five day reporting period. All diaries were completed during the week commencing the 26th March 2012. One nurse completed the diary during the week commencing the 23rd April 2012 as she was on leave during the original data collection week. This data provides an overview of the "typical" activities currently undertaken by nurses in rural general practice ${ }^{[16]}$. The activities recorded in the diaries are not considered advanced practice for general practice nurses.

A limitation of the diaries is that the precise time taken for activities was not recorded but this was a practical decision made early in the study because of the inaccuracy of such data and the impost on participant time. 
Interviews: 16 Practice nurses, 4 practice principals (one unavailable) and 5 practice managers were interviewed using a focussed interview guide that covered the following: the role of practice nurses, the methods adopted by practice nurses to ensure practice is contemporary and evidenced based, the support provided for professional development, potential for role expansion, advancement of practice and specialisation. Individual interviews lasting thirty minutes were conducted either at the practice or on the telephone, on two occasions focus groups of one hour duration were held with practice nurses. Demographic data including years since registration, years in general practice, years in current general practice and hours worked per week were collected.

A mini environmental scan, inclusive of local population serviced by the general practice, was undertaken to provide context for each of the cases.

\subsection{Data analysis}

Job descriptions for practice nurses from each facility were reviewed to provide information on practice nurses' current roles and this information was subsequently compared with the diary data and the generated interview data. The job descriptions were generic, and in all rural settings had not been updated in the past twelve months.

Data from the diaries were entered onto an excel spreadsheet, and aggregated. Interview and focus group data were recorded, transcribed and subsequently analysed using a thematic analysis approach ${ }^{[17]}$. Data was coded and then codes were systematically compared and linked to form themes. Both barriers to, and facilitators that support advancing practice were identified. Position descriptions were reviewed using content analysis procedures and then compared with the activity data generated from the diaries and the interviews. These data were compared with a standardised job description and the Competency Standards for Nurses in General Practice.

\subsection{Participants}

\subsubsection{Cases}

Five general practices (see Table 1) agreed to participate in the study. For the purposes of site selection, the Australian Standard Geographical Classification (ASGC) was used to ensure that the diversity of general practice settings was representative. A metropolitan located general practice and a corporate rural practice were included to reflect the diversity of practice locations and emerging new practice organisational structures. The general practice selection was approved by the funding agency.

Table 1. Profile of GP practice $1-5$

\begin{tabular}{|c|c|c|c|c|c|}
\hline & Practice 1 & Practice 2 & Practice 3 & Practice 4 & Practice 5 \\
\hline RNs & 5 & 5 & 3 & 1 & 1 \\
\hline GPs & 14 & 8 & 6 & 1 & 1 \\
\hline ENs & - & - & 1 & & 1 (relief) \\
\hline Population & 4,317 & 61,441 & 4,429 & 2,187 & 1,584 \\
\hline $\begin{array}{l}\text { Average age of } \\
\text { population }\end{array}$ & 31 & 31 & 41 & 41 & 37 \\
\hline $\begin{array}{l}\text { Other local Health } \\
\text { Services }\end{array}$ & $\begin{array}{l}\text { Other GP } \\
\text { practices, large } \\
\text { tertiary and private } \\
\text { hospital }\end{array}$ & $\begin{array}{l}\text { Other GP } \\
\text { practices, large } \\
\text { public and private } \\
\text { hospital. Spec and } \\
\text { diagnostic services }\end{array}$ & $\begin{array}{l}\text { Small rural } \\
\text { hospital }\end{array}$ & $\begin{array}{l}\text { One other GP } \\
\text { practice, } \\
\text { and a } \\
\text { multi-purpose } \\
\text { service }\end{array}$ & $\begin{array}{l}\text { Small } \\
\text { multi-purpose } \\
\text { service. }\end{array}$ \\
\hline GP training & Yes & Yes & & & \\
\hline Pre-service nursing & Yes & Yes & & & \\
\hline
\end{tabular}




\subsubsection{Participants}

In total 33 general practice staff agreed to be involved in interviews, either one on one or in two focus groups. Sixteen part-time nurses also completed work diaries over the space of one week. One validation focus group was attended by 11 nurses at the conclusion of the study, this group was convened to share emerging results and check for practical plausibility. Four practice principals and five practice managers were interviewed regarding their perception of the current role of the practice nurse and the potential for advanced practice.

The majority of nurses work part-time (87.5\%) compared with National General Practice Network data estimate of 76.9\% in 2009, which is consistent with the average number of hours recorded in the diaries which was 24.2. As the majority of practice nurses are employed part-time which is consistent with the national data that indicate $76.9 \%$ of practice nurses are part-time employees ${ }^{[18]}$, diary entries ranged from 1 day -5 days. $87.5 \%$ of the practice nurses worked part-time. The average hours per week they worked was 24.2. On average the practice nurses have worked in general practice for 7.3 years and in the current workplace for 6.3 years.

There were some differences between registered nurses and endorsed enrolled nurses worthy of note although the sample size overall was small. The registered nurses have been registered for an average of 29 years while the endorsed enrolled nurses have been licensed for practice on average for 8.5 years.

Table 2 details the activities that practice nurses recorded in the work diaries. This data has been aggregated and averaged to reflect general categories of work activity. Health assessment of patients that involved general health checks for industry, related to funding streams and disease specific such as diabetes, cardiovascular and respiratory illnesses were the most significant activities performed by the practice nurses.

Table 2. Nurses in general practice work activity

\begin{tabular}{ll}
\hline Work activity & Average Nos. activities / wk \\
\hline Health assessments / management plans & 2.1 \\
Injections (Intramuscular, sub-cutaneous): & 4.8 \\
Vaccination (Flu) & 3.5 \\
IMI Child Immunisation & .4 \\
IMI Injections & .9 \\
Direct patient care & 3.9 \\
Wound assessment and dressing & \multicolumn{2}{c}{1.2} \\
Other incl. ear syringing, spirometry, ECG & 2.7 \\
Health Education/Promotion & 1.8 \\
Maintenance (equipment/physical resources) & 3.3 \\
Administrative duties & 4 \\
Nurse Professional Development & .1 \\
\hline Total & 20 \\
\hline
\end{tabular}

Table 2 illustrates the clusters of activities that practice nurses undertake on a weekly basis. The hours dedicated to each cluster of activity are an average of time spent. In total nurses spend 20 hours each week on these activities.

During this data collection period all general practices were offering influenza vaccination. This single intervention accounted for the most frequent activity performed by the practice nurses. However during the data collection period some practices had not started their programs bringing the aggregate scores down. On average each nurse performed 3.5 flu 
vaccinations per week. Practice nurses gave on average 4.8 intramuscular injections (that are inclusive of 'flu vaccines, child immunisations and other medications such as travel vaccines, vitamin supplements) per week.

Practice nurses performed on average 3.9 activities involving direct patient care that included, but was not limited to, dressing and assessment of wounds, spirometry testing, ECG monitoring, screening hearing, urine testing, suture removal, ear syringing and assisting the general practitioner with minor procedures. Dressing and assessing wounds was the most frequently performed work by the nurses in this cluster of activity.

Administrative duties included completing patient's notes, drafting letters to patients about appointments, telephone calls to patients' other providers, liaising with doctors and covering reception when required. Many of the practice nurses were involved in administrative work related to collating and/or itemising their activities against Medicare items for billing purposes.

A significant amount of the work (3.3 on Table 2 or $16.5 \%$ of recorded activities) was related to cleaning clinical areas, packaging and sterilising instruments, stocking and restocking supplies and monitoring equipment including fridges in which vaccines were kept.

\section{Findings}

\section{The emergent themes were: Activities, Advanced Practice and Continuing Professional Development.}

Sixteen practice nurses all female (14 registered nurses and 2 medication endorsed enrolled nurses) completed diaries for a maximum period of five consecutive days.

Activities: All interviewees when talking about the work undertaken by practice nurses described activities that corresponded to the activities recorded in the diaries. Before discussing advanced roles the nurses and practice managers referred to the activities that supported or were required by the medical staff of the practice. Participating nurses reported that working in general practice settings is intensive; workflow is constant with little down time available.

The work is talked about by the nurses as predominantly being patient care although there is a fair amount of administration and clearing up recorded in the diaries (see Table 2). Practice managers and principals referred to nurses' contribution to leadership, quality assurance and governance.

Table 2 details the activities that practice nurses recorded in the work diaries. This data provides an overview of the "typical" activities currently undertaken by nurses in rural general practice ${ }^{[16]}$. The activities recorded in the diaries are not considered advanced practice for general practice nurses. The data has been aggregated and averaged to reflect general categories of work activity. Health assessment of patients that involved general health checks for industry, related to funding streams and disease specific such as diabetes, cardiovascular and respiratory illnesses were the most significant activities performed by the practice nurses.

During this data collection period all general practices were offering influenza vaccination. This single intervention accounted for the most frequent activity performed by the practice nurses. Other direct clinical activities the practice nurses engaged in ranged from completing health assessments, health interventions such as ear syringing, and suture removal and wound dressings. Dressing and assessing wounds was the most frequently performed work by the nurses in this cluster of activity. They also assisted the general practitioner with minor procedures.

Administrative duties included completing patient's notes, drafting letters to patients about appointments, telephone calls to patients' other providers, liaising with doctors and covering reception when required. Many of the practice nurses were 
involved in administrative work related to collating and/or itemising their activities against Medicare items for billing purposes.

A significant amount of the work (3.3 on table 2 or $16.5 \%$ of recorded activities) was related to cleaning clinical areas, packaging and sterilising instruments, stocking and restocking supplies and monitoring equipment including fridges in which vaccines were kept.

Job descriptions: Minor differences were found in the position descriptions and all appeared to stem from the standardised document. On the whole specific tasks are not referred to in the documents leaving interpretation of advanced roles to the individual nurse and routine practices of the organisation.

Advanced Practice: Nurses and Practice Principals expressed the view that the PNIP (Practice Nurse Incentive Program) model of funding (a block funding model that in January 2012 replaced the old Medicare item numbers) was impacting adversely on the work that the practice nurses can do. They considered that this system limits the work that nurses in general practice can perform. Practice managers and principals linked this to the income that nurses could generate for the practice. The managers were not quite as specific as the principals but they did relate nursing activities to income and stated that advancing practice should be of benefit to the general practice.

Advanced nursing practice was considered to be aligned to experience and specialisation such as diabetes and wound management and indeed wound management was given as an example of advanced practice by one of the practice principals. Understanding of advanced practice varied amongst the participants. There was a view that the nurses were so busy there was nothing more they could do and in addition working part-time limited their motivation and ability to advance. However, nurses and managers did identify outreach and specialist clinics as potential options for practice advancement. Examples of diabetes education and assessment of over 75 year olds were again cited.

The nurses gave examples of what they view as advanced practice, making assessments in people's homes and immunising older people in residential aged care facilities. There were examples given of nurses taking opportunities to solve problems for patients circumventing a need to see the doctor. The nurse who described how she made a point of talking to patients in the waiting room to pick up on how they were doing was an example of an expanded nursing role ${ }^{[19]}$.

Some practices had introduced new models of care that largely involved practice nurses in expanded roles with older people but additional funding streams initiated this rather than perceived community need or nursing expertise. There was also mention of employing nurses with "acute experience" into these roles rather than encouraging current practice nurses to advance. Some nurses reported that it was difficult to implement change in their workplace as the doctors were happy with the way the practice operated. Others indicated that there was a willingness by their practice to engage with all staff to promote change aimed at improving efficiency and service delivery. For example a proactive practice conducted focus groups with patients every six months to identify options for enhancing services. The nurses who worked in this practice reported feeling empowered to explore options for new ways of delivering care and stated new nursing roles were implemented including an outreach service for patients aged 75 years and above. They also talked about their involvement in a research study that enhanced their work with clients at risk of, or suffering from cardiovascular disease.

An example of the influence of funding was the home visiting programs for over 75 year old patients. This type of initiative was identified by the principals as a potential opportunity for nurses to advance their practice (RA3). On the other hand all of the general practices indicated that performing pap smears was not currently part of the practice nurse's role. This was either because they (the practice nurses) did not want to take on the role or this was the role of a medical practitioner. Advanced practice and CPD was noted to be a choice for nurses rather than a responsibility that should be within the scope of a registered nurse. 
Taking on a leadership role and engaging in the support of other, and new staff were highlighted as demonstrating advanced practice. One practice principal indicated that the practice nurses manage the accreditation process and ensure that all staff are aware of the process and are familiar with the quality assurance measures adopted. She commented that

“...they do this well” (PPRA1). In this practice, a practice nurse chairs the medical practitioner meeting which the practice principal argued improved the efficiency of the practice and ensured that the medical staff were well informed (PPRA1).

Continuing Professional Development: Financial support and time release to attend CPD training and education programs were considered worthwhile investments by all participants. The practice principals qualified the support the practice provided to practice nurses to participate in CPD with "if the nurse wanted to". The nurses stated a preference for short courses but also described a broad range of learning technologies that they use. Postgraduate courses were not identified by the interviewees as preparation for advanced practice although there were a number of RNs in the group that had previously obtained specialist university qualifications. They recognised the need for education before extending or expanding their roles. Some of the nurses undertook online CPD programs, or read online and hard copy information to which their workplaces subscribed. Consulting with the doctors was also identified as a method of ensuring currency of practice. Another nurse commented that participating in targeted CPD such as asthma education was sometimes in response to the needs of the doctors:

We were going to do Asthma education but it hasn't been organised. We need to sit down with the practice manger and work out what the doctors want us (the practice nurses) to do (PNRA29).

\section{Barriers and enablers}

Following the initial analysis and reporting of the results the research team analysed perceived barriers and facilitators for advanced practice. These factors are summarised in Table 3.

Personal: Positive attitudes to advanced practice included a range of ways the nurses maintain and extend their knowledge. The nurses interviewed were well aware of modern resources and how to use them. However there is a prevailing attitude that advancing practice is a choice for nurses and also doctors to make. There is a satisfaction expressed by all interviewees with the status quo and this quells the impetus for change - the nurses and practice managers are cognisant that the nurses are busy and there is little room to fit in extra duties. The majority of the nurses work part-time and this limits their ability to take up opportunities for a more demanding role.

Workplace: The nurses have a well-respected place in the general practice team. Colleagues generally offer support and there is in principle agreement that there is potential to advance nursing roles. Protocols and systems, updated position descriptions are available and while these differ they all correspond to the standards and scope of practice of registered nurses. Nurses, particularly those in single practices, find themselves a 'jack of all trades'. Much of the work is described as activities or tasks and this detracts from the knowledge and skills required. For example wound management was declared an advanced role and yet holistic care was not included in the description of this work. Failure to express the intricacies of practice make it difficult to claim it as nursing let alone advanced nursing ${ }^{[19,20]}$.

Policy: Funding that is tied to more than episodic care should be an enabler to expanded advanced practice. However, because PNIP has replaced hard won item numbers it is considered a barrier by nurses and practice principals. Currently there is no expectation that nurses will advance their knowledge and skills and take on more responsibility for meeting community needs. Nor is there any obvious requirement for them to account for new practices. Initiatives that encourage advanced practice and that are funded are obvious enablers, but the work tends to go to nurses who express an interest or who are recruited to the position and specialist area.

Blurring of roles of Nurse Practitioner and General Practice Nurse with advanced skills is a barrier to progress. There is an impression that a masters degree is necessary and this is not necessarily the case. 
Table 3. Enablers and barriers impacting on the advancement of practice nursing

\begin{tabular}{|c|c|c|}
\hline Categories & Enablers & Barriers \\
\hline \multirow{4}{*}{ Personal } & $\begin{array}{l}\text { Personal motivation to self improvement - } \\
\text { start by deciding what you want to do } \\
\text { Being a reflective practitioner }\end{array}$ & Lack of motivation to change practice \\
\hline & Creating opportunity & \multirow{3}{*}{$\begin{array}{l}\text { Personal circumstances e.g. inability to study } \\
\text { due to family commitments }\end{array}$} \\
\hline & Knowing the system, the politics & \\
\hline & $\begin{array}{l}\text { Knowing you make a difference- reflected } \\
\text { in patient outcomes }\end{array}$ & \\
\hline \multirow{9}{*}{ Workplace } & $\begin{array}{l}\text { Guidelines about advanced practice, } \\
\text { available to GPs as well }\end{array}$ & $\begin{array}{l}\text { Only nurse in the practice - trying to do } \\
\text { everything -treading water slowly }\end{array}$ \\
\hline & \multirow{4}{*}{$\begin{array}{l}\text { Structure of organization - encouraging } \\
\text { Support of work colleagues, and wider } \\
\text { networks } \\
\text { Individualised position descriptions that are } \\
\text { regularly updated }\end{array}$} & \multirow{3}{*}{$\begin{array}{l}\text { Generic position descriptions not regularly } \\
\text { reviewed } \\
\text { Lack of team support }\end{array}$} \\
\hline & & \\
\hline & & \\
\hline & & Workload \\
\hline & \multirow{4}{*}{$\begin{array}{l}\text { Access to and support to engage in CPD } \\
\text { Supportive working environment } \\
\text { Relieving nurses of technical duties to } \\
\text { focus on direct patient care }\end{array}$} & Fee for service model \\
\hline & & Task orientated perception of nurses role by the \\
\hline & & doctors \\
\hline & & Doctors not aware of what nurses can do. \\
\hline \multirow{3}{*}{ Policy } & $\begin{array}{l}\text { PNIP funding that promotes advancement } \\
\text { of nursing practice that is not tied to }\end{array}$ & $\begin{array}{l}\text { Misunderstanding of the PNIP payment system, } \\
\text { what it covers and how it can be used. }\end{array}$ \\
\hline & episodic care & \\
\hline & $\begin{array}{l}\text { Pathways that signpost expectations for } \\
\text { advancing practice }\end{array}$ & $\begin{array}{l}\text { Desire to have Medicare items to track nurses' } \\
\text { activity }\end{array}$ \\
\hline
\end{tabular}

\section{Discussion}

The work of the nurses in the five case studies is intensive and activity based. The intensity or busyness of the role provides a legitimate reason for the status quo. Practices that genuinely wish to advance general practice nursing roles need to question some activities and delegate the activities to others in order to make room for new roles. Position descriptions and performance agreements for all general practice nurses should include provision for and an expectation that their role will advance as the nurse gains experience in general practice and advanced knowledge. Interviewees did not refer to either performance agreements or position descriptions when describing practice nurse roles or advanced practice in this study which would indicate that these documents are not guiding practice and professional development as intended.

The emphasis on activities maybe, in part, a result of the template in the work diaries but the results are matched by the interview data (i.e. the interviewees all described the work as a series of tasks). The interviews did show signs that the work of the general practice nurse is evolving and as it does so they are taking on work that eases the load of general practitioners. Whether this progress is fast enough to meet the increasing needs of the community is a moot point.

What is patently missing is an incentive for nurses in general practice to take up advanced roles. There does not appear to be a great demand for them to do so from either the practice principals or the practice managers and besides incentive funding to the practice there is nothing tangible for the nurses to do so. 
The recommendations from this study are that resources should be available in the general practice to support advanced practice.

- a framework for advancing nurses in general practice that becomes a pathway for nurses choosing a career in general practice nursing.

- a position description for the advanced role and

- a range of opportunities for nurses to develop skills of advanced practice both educational and experiential including performance agreements that expect incremental advancement from all staff.

These recommendations have been incorporated into a larger set of recommendations currently advocated to support the advancement of general practice nursing in rural areas in Australia. The research was constrained to some extent by the tender brief that identified key stakeholders for participation in the study and the timeframe. Recordings in the diaries were kept to a minimum to improve compliance but this decision meant that there were no timings allocated to various activities.

\section{Conclusion}

The participants in the study worked with us to examine the reality of general practice in rural Australia. While case studies have limitations in terms of generalizability the findings have high contextual credibility ${ }^{[21]}$. The barriers and enablers to advanced practice in rural general practices are specific and it is only by investigating everyday practice and respecting the perspective of all players that a picture that resonates with the protagonists is possible. This paper adds to the body of knowledge specific to rural general practice in Australia and to a lesser extent urban general practice. The practical implications of this study include recommendations for development of several resources, including a framework for advancing nurses in general practice, an advanced general practice nurse position description, and interventions for general practices to support advanced roles for nurses.

\section{Acknowledgements}

This study was commissioned by the Australian General Practice Network (AGPN) and supported by the Australian Primary Health Care Research Institute (APHCRI, ANU).

The authors acknowledge the generous contributions made by staff of the general practices that participated in the study.

\section{Declarations of interest}

The authors declared no conflict of interest.

\section{References}

[1] Halcomb EJ, Davidson PM. Strategic directions for developing the Australian general practice nurse role in cardiovascular disease management. Contemporary Nurse: A Journal for the Australian Nursing Profession. 2007; 26(1): 125-135.

http://dx.doi.org/10.5172/conu.2007.26.1.125

[2] Halcomb EJ, Patterson E, Davidson PM. Evolution of practice nursing in Australia. Journal of Advanced Nursing. 2006; 55(3): 376-388. http://dx.doi.org/10.1111/j.1365-2648.2006.03908_1.x

[3] Australian General Practice Network. Nursing in General Practice: Recruitment and Orientation Resource: A guide for general practices, practice nurses and divisions of general practice. Canberra: Australian General Practice Network; 2009.

[4] Keleher H, Parker R, Abdulwadud O, Francis K. Systematic review of the effectiveness of primary care nursing. International Journal of Nursing Practice. 2009; 15(1): 16-24. http://dx.doi.org/10.1111/j.1440-172X.2008.01726.x

[5] Royal College of Nursing. Nursing in General Practice: A guide for the general practice team. Canberra: Royal College of Nursing; 2005. 
[6] Phillips C, Pearce C, Dwan K, Hall S, Porritt J, Yates R, et al. Charting New Roles for Australian General Practice Nurses: A multicentre qualitative study. Canberra: Australian Primary Health Care Research Institute; 2008.

[7] Atkin K, Lunt N. Negotiating the role of the practice nurse in general practice. Journal of Advanced Nursing. 1996; 24(3): 498-505. http://dx.doi.org/10.1046/j.1365-2648.1996.02179.x

[8] Halcomb EJ, Davidson PM, Griffiths R, Daly J. Cardiovascular disease management: time to advance the practice nurse role? Australian Health Review. 2008; 32(1): 44-55. PMid:18241148 http://dx.doi.org/10.1071/AH080044

[9] Halcomb EJ, Davidson PM, Salamonson Y, Ollerton R, Griffiths R. Nurses in Australian general practice: implications for chronic disease management. Journal of Clinical Nursing. 2008; 17(5a): 6-15. PMid:18298752 http://dx.doi.org/10.1111/j.1365-2702.2007.02141.x

[10] Caldow J, Bond C, Ryan M, Campbell NC, Miguel FS, Kiger A., et al. Treatment of minor illness in primary care: a national survey of patient satisfaction, attitudes and preferences regarding a wider nursing role. Health Expectations. 2007; 10(1): 30-45. PMid:17324193 http://dx.doi.org/10.1111/j.1369-7625.2006.00422.x

[11] Hegney D, Eley R, Buikstra E, Rees S, Patterson E. Consumers' Level of Comfort with an Advanced Practice Role for Registered Nurses in General Practice: A Queensland, Australia, Study. Australian Journal of Primary Health. 2006; 12(3): 44-51. http://dx.doi.org/10.1071/PY06044

[12] Redsell S, Stokes T, Jackson C, Hastings A, Baker R. Patients' accounts of the differences in nurses’ and general practitioners' roles in primary care. Journal of Advanced Nursing. 2007; 57(2): 172-180. PMid:17214753 http://dx.doi.org/10.1111/j.1365-2648.2006.04085.x

[13] Mills J, Fitzgerald M. The changing role of practice nurses in Australia: an action research study. Australian Journal of Advanced Nursing. 2010; 26(1): 5.

[14] Galvin K, Andrewes C, Jackson D, Cheesman S, Fudge T, Ferris R, et al. Investigating and implementing change within the primary health care nursing team. Journal of Advanced Nursing. 1999; 30(1): 238-247. PMid:10404001 http://dx.doi.org/10.1046/j.1365-2648.1999.01069.x

[15] Stake R. Multiple Case Study Analysis. New York: Guilford; 2006.

[16] Paolisso M, Hames R. Time diary versus instantaneous sampling: A comparison of two behavioural research methods. Field Methods. 2010; 22(4): 357-377. http://dx.doi.org/10.1177/1525822X10379200

[17] Taylor B, Kermode S, Roberts K. Research in Nursing and Health Care: Evidence for practice (3 ed.). Melbourne, Australia: Thomson; 2006.

[18] Australian General Practice Network. 2009 National Practice Nurse Workforce Survey. Maunka, Canberra. 2009.

[19] Pearson A. Expansion and extension of rural health workers roles to increase access to health services in rural areas. Paper presented at the 2nd National Rural Health Conference, Armidale. 1993.

[20] Pearson A, Vaughan B, Fitzgerald M. Models for Nursing Practice. London: Butterworth-Heinemann; 2006.

[21] Yin R. Case Study Research (4 ed.). Thousand Oaks: Sage; 2008. 